\title{
Hydrolase-Like Activity Provided by Zinc(II) and Oleoyl-Histidine at Liposome Membrane Surface
}

\author{
Atsushi Tauchi, Keishi Suga ${ }^{(1)}$ and Hiroshi Umakoshi * \\ Division of Chemical Engineering, Graduate School of Engineering Science, Osaka University, \\ 1-3 Machikaneyama-cho, Toyonaka, Osaka 560-8531, Japan; atsushi.tauchi@cheng.es.osaka-u.ac.jp (A.T.); \\ keishi.suga@cheng.es.osaka-u.ac.jp (K.S.) \\ * Correspondence: umakoshi@cheng.es.osaka-u.ac.jp; Tel.: +81-6-6850-6287
}

Received: 20 April 2018; Accepted: 11 June 2018; Published: 13 June 2018

\begin{abstract}
Carbonic anhydrase (CA) is a hydrolase enzyme possessing an active center composed of three histidines (His), zinc(II) $\left(\mathrm{Zn}^{2+}\right)$, and a hydration water. Here we report the hydrolase-like catalytic activity provided by the oleoyl-histidine (O-His) modified on liposome membranes. O-His was synthesized by the amide bond between oleic acid and His, and was incorporated into 1,2-dioleoyl-sn-glycero-3-phosphocholine (DOPC) and 1,2-dipalmitoyl-sn-glycero-3-phosphocholine (DPPC) liposomes. The hydrolysis of $p$-nitrophenylacetate was promoted by O-His modified DOPC liposomes in the presence of $\mathrm{Zn}^{2+}$. The formation of the active center was revealed by UV resonance Raman spectra. We conclude that the liposome membrane surface can be utilized as a platform for artificial hydrolysis reactions by modifying essential ligands inspired from natural enzymes.
\end{abstract}

Keywords: artificial enzyme; liposome; membrane interface; histidine; Zinc(II)

\section{Introduction}

Carbonic anhydrase (CA) is a typical metalloenzyme that has an active site consisting of zinc(II) $\left(\mathrm{Zn}^{2+}\right)$, three imidazole residues of L-histidine (His), and a hydration water [1]. The CA in vivo has the ability of converting $\mathrm{CO}_{2}$ to $\mathrm{HCO}_{3}{ }^{-}$and $\mathrm{H}^{+}$, which plays a central role in controlling $\mathrm{pH}$ in the cell [2]. Currently, several researchers have attempted to mimic the activity of $\mathrm{CA}$ in the industrial field: the active center like $\mathrm{Zn}$-imidazole complex was created on solid supported catalysis to reduce $\mathrm{CO}_{2}$ exhausted from the factory [3,4].

In the enzymatic reaction of $\mathrm{CA}$, the diffusion of $\mathrm{CO}_{2}$ is a rate-limiting step due to poor solubility of $\mathrm{CO}_{2}$ in water. The use of an organic solvent, for example, solves this problem, while it might reduce the enzymatic activity drastically due to denaturation [5]. In addition, the active site becomes unstable by immobilization of the enzyme on solid surface. To overcome such problems, self-assemblies (micelles and emulsions) have been used to develop technologies with high efficiency and selectivity [6-8]. It has been reported that the active site, similar to that of CA, was created by bolaamphiphile [9]. However, this method has a problem: the size and structure of the active center could not be adjusted because of the solid-like rigid surface. Therefore, in this study, the "flexible" interface of self-assembly was used as a rationally-designed platform for the CA-like hydrolysis reaction.

A liposome membrane is a vesicular self-assembly that is constructed of phospholipids in an aqueous solution. The self-assembly surface can be applied to induce emergent properties, such as molecular recognition and molecular conversion [10]. For example, the chiral selective adsorption of L-amino acid could be proceeded at a liposome membrane interface [11]. Moreover, in the case of a liposome membrane, the phase state, which affects fluidity, polarity, and micro size domain, can be easily controlled by their composition and temperature $[12,13]$. Therefore, it is considered that a liposome membrane interface is a superior platform for constructing the active site like $\mathrm{Zn}$-imidazole 
complex, since the localization of the ligands can be dynamically controlled depending on the liposome membrane properties (e.g., fluidity and polarity).

In the active center of CA, the $\mathrm{Zn}$ (II) binding pocket consists of both a polar surface and a nonpolar surface, which provides an affinity between the ligand and metal ion via non-covalent interactions [14]. Inspired from CA, herein the histidine derivative modified with oleoyl group (oleoyl-histidine, O-His) was synthesized. Although O-His itself showed less solubility in water, the incorporation of O-His in the liposome membranes enables not only the dispersal of O-His in water, but also the imidazole groups are aligned in the polar region at the membrane surface. By adding $\mathrm{Zn}^{2+}$, the creation of the active site like Zn-imidazole complex was evaluated from (i) hydrolysis activity and (ii) varied membrane properties.

\section{Results and Discussion}

\subsection{Evaluation of Hydrolysis Catalytic Activity}

CA can promote the hydrolysis of $p$-nitrophenylacetate ( $p$-NPA). Thus, to monitor the hydrolysis of $p$-NPA, the catalytic activity of the Zn-imidazole complex can be evaluated [15]. The production rates of $p$-nitrophenol $(p-\mathrm{NP})$ were estimated for free His and O-His modified 1,2-dioleoyl-sn-glycero-3-phosphocholine (DOPC) liposomes (Figure 1a). In the cases of $\mathrm{Zn}^{2+}$ only, and free His $+\mathrm{Zn}^{2+}$, the production rates of $p$-NP were almost the same, while it was increased by the $\mathrm{O}$-His modified DOPC liposome with $\mathrm{Zn}^{2+}$. Based on these results, a Lineweaver-Burk plot was made to evaluate the catalytic activity $\left(k_{\mathrm{cat}} / K_{\mathrm{m}}\right)$ and substrate affinity $\left(1 / K_{\mathrm{m}}\right)$ (Figure $\left.1 \mathrm{~b}\right)$. The slope and intercept of the O-His modified DOPC liposome were smaller and bigger than those of $\mathrm{Zn}^{2+}$ only and free His $+\mathrm{Zn}^{2+}$ solution, respectively. The substrate affinity $\left(1 / K_{\mathrm{m}}\right)$ and catalytic activity $\left(k_{\mathrm{cat}} / K_{\mathrm{m}}\right)$ are summarized in Figure 1c. In the absence of liposome membrane, Lineweaver-Burk plots were almost the same both in the $\mathrm{Zn}^{2+}$ only solution and in the free His $+\mathrm{Zn}^{2+}$ solution, suggesting that the interaction between $\mathrm{Zn}^{2+}$ and the imidazole group of His is weak in solution. In the absence of $\mathrm{Zn}^{2+}$, a slight increase in $k_{\text {cat }} / K_{\mathrm{m}}$ and $1 / K_{\mathrm{m}}$ was observed in 1,2-dipalmitoyl-sn-glycero-3-phosphocholine (DPPC)/O-His liposomes, indicating that the O-His itself has a small effect on the hydrolysis. In the presence of $\mathrm{Zn}^{2+}$, O-His modified liposomes obviously increased both catalytic activity $\left(k_{\text {cat }} / K_{\mathrm{m}}\right)$ and, especially, substrate affinity $\left(1 / K_{\mathrm{m}}\right)$. The O-His modified DPPC liposome showed a bigger $1 / K_{\mathrm{m}}$ value than the O-His modified DOPC liposome (Figure 1c, supporting information Figure S3).

Earlier, it was reported that the $p$-NPA hydrolysis is promoted by the constructed $\mathrm{Zn}$-imidazole complex [9]. Moreover, the immobilization of an enzyme at the membrane interface made the enzyme reaction rate higher [16]. The reported hydrolysis activities are summarized in Table 1. Based on $k_{\text {cat }} / K_{\mathrm{m}}$ values, the CA (enzyme) shows the value of 453.2 [3], while an artificial enzyme shows that of 0.73 [9]. As compared to Kim et al. [9], the substrate affinity $\left(1 / K_{\mathrm{m}}\right)$ of DOPC/O-His with $\mathrm{Zn}^{2+}$ was superior. Therefore, the imidazole group could be immobilized at the liposome membrane surface, which made the formation of $\mathrm{Zn}$-imidazole complex easier, and increased the affinity between the active site and substrate. However, the maximum reaction rate $\left(V_{\max }\right)$ was decreased. O-His molecules could be distributed between the two (inner and outer) layers of the liposomes bilayer: the O-His exposed to the external medium is active to the reaction while the O-His distributed in the inner leaflet is inactive, because hydrophilic materials $\left(\mathrm{Zn}^{2+}\right.$, substrate) are less permeable across the lipid bilayer. Roughly, less than half of the O-His molecules incorporated into the liposome membrane resulted in a three times higher $k_{\text {cat }} / K_{\mathrm{m}}$ value, as compared to free His molecules. The substrate $p$-NPA is hydrophilic, so only small amount of $p$-NPA can potentially be adsorbed onto liposome membranes: about $7 \%$ of $p$-NPA (initial conc. $2.5 \mathrm{mM}$ ) adsorbed on DOPC liposome (total lipid: $2.5 \mathrm{mM}$ ). In liposome system, the substrate adsorption could be a rate-limiting step, so that the reaction rate decreased at a high concentration of substrate. Therefore, the hydrolysis of $p$-NPA could be promoted at the liposome membrane surface by the formation of $\mathrm{Zn}$-imidazole complex. 
Table 1. Hydrolysis activities of carbonic anhydrase (CA) and artificial enzymes.

\begin{tabular}{ccc}
\hline & $\mathbf{1 / K} \boldsymbol{K}_{\mathbf{m}}\left(\mathbf{m M}^{-\mathbf{1}}\right)$ & $\boldsymbol{k}_{\text {cat }} / \boldsymbol{K}_{\mathbf{m}}\left(\mathbf{M}^{-\mathbf{1}} \mathbf{s}^{-\mathbf{1}}\right)$ \\
\hline CA [3] & 0.104 & 453.2 \\
His-C7 (bolaamphiphile) $+\mathrm{Zn}^{2+}[9]$ & 0.00917 & 0.73 \\
DOPC/O-His $+\mathrm{Zn}^{2+}$ & 1.02 & 1.20 \\
\hline
\end{tabular}

(a)

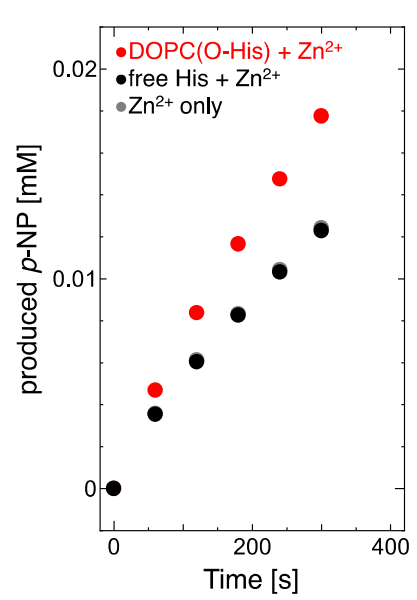

(b)

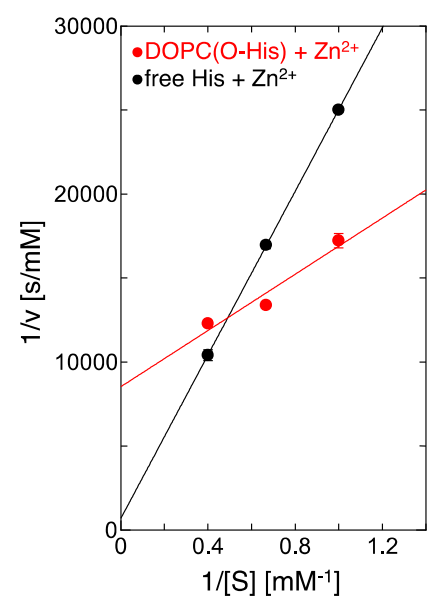

(c)

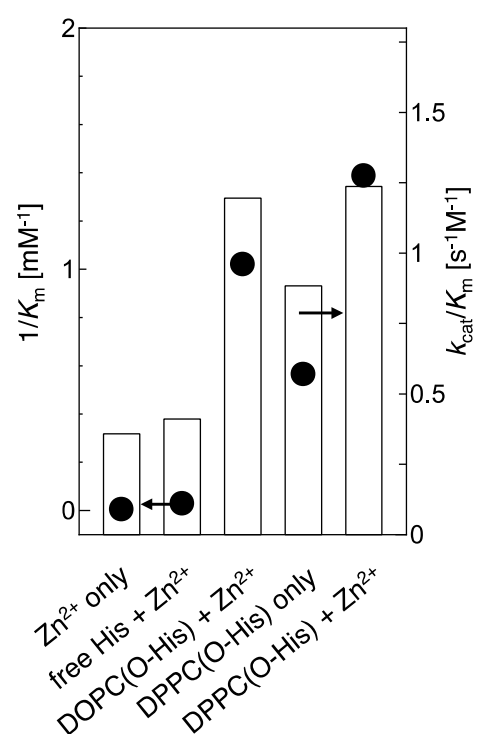

Figure 1. (a) Time course of $p$-NP production; (b) Lineweaver-Burk plot for 1,2-dioleoyl-sn-glycero -3-phosphocholine (DOPC) (O-His $20 \mathrm{~mol} \%$ ) and free His. The standard deviations were less than 0.05 ; (c) Comparison of $1 / K_{\mathrm{m}}$ ( $y$ axis) and $k_{\text {cat }} / K_{\mathrm{m}}$ ( $R$ axis) values. As a negative control, the free His (as amino acid) was directly added into the reaction mixture. $\left[\mathrm{Zn}^{2+}\right]=0.1 \mathrm{mM}$, [O-His] $=0.3 \mathrm{mM}$ for DOPC (O-His $20 \mathrm{~mol} \%$ ) and DPPC (O-His $20 \mathrm{~mol} \%)$. Experiments were conducted at $25^{\circ} \mathrm{C}$.

\subsection{Evaluation of Complex Creation}

For the evaluation of the Zn-imidazole complex formation, UV resonance Raman spectroscopy measurements were carried out (Figure 2). In the case of the O-His modified DOPC liposome suspension, significant peaks were not observed at the range from 350 to $1800 \mathrm{~cm}^{-1}$. By adding $\mathrm{Zn}^{2+}$, two peaks at $614 \mathrm{~cm}^{-1}$ and $1416 \mathrm{~cm}^{-1}$ were generated: these peaks were assigned as the imidazole ring and N-H moiety, respectively $[17,18]$. Because the lipid molecules (DOPC, O-His) are almost inactive for Raman in our experimental conditions, the generated peaks indicate the formation of Zn-imidazole complex. The O-His modified DOPC liposome showed a stronger peak at $1416 \mathrm{~cm}^{-1}$ than O-His modified DPPC liposome (Figure 2b). The Raman peak intensity increased in proportion to the $\mathrm{O}$-His amount (Figure 2c). These data suggest that a large number of $\mathrm{Zn}$-imidazole complex was formed on the O-His modified DOPC liposome, while the $1 / K_{m}$ value of the O-His modified DOPC liposome was smaller than the O-His modified DPPC liposome. Considering the catalytic activities in the presence of $\mathrm{Zn}^{2+}$ (Figure 1c), the formation of $\mathrm{Zn}$-imidazole complex on the liposome surface plays an important role on the hydrolysis reaction of $p$-NPA. However, the amount of active site, which is relevant to the coordination number of O-His to $\mathrm{Zn}^{2+}$, is still unclear. The membrane properties of liposome; e.g., polar environment-differ between the DOPC and DPPC liposomes. Considering the local environment around the active center, the membrane property could be a factor in regulating the hydrolysis reaction. 
(a)

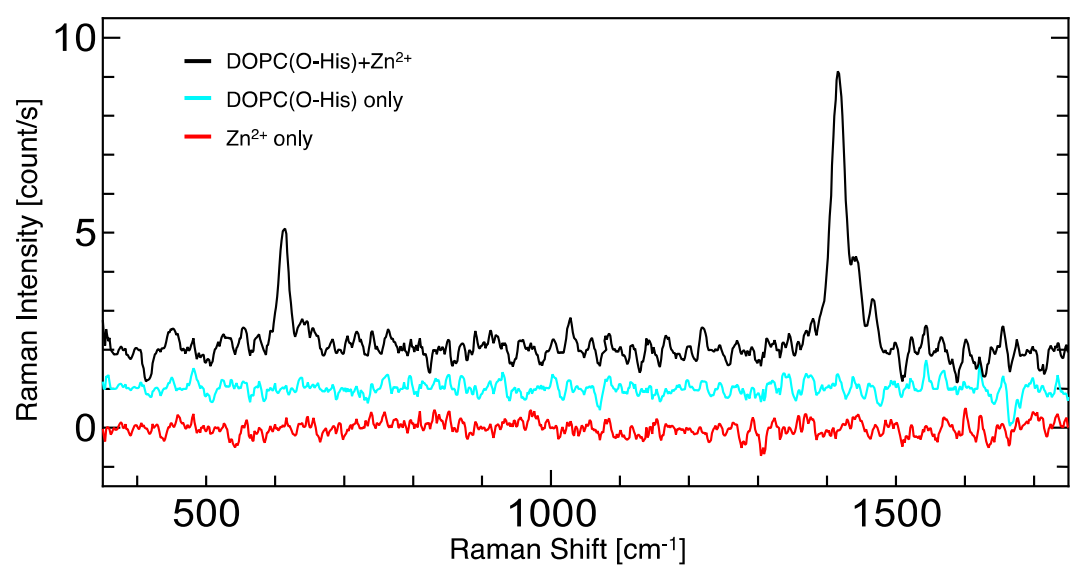

(b)

(c)
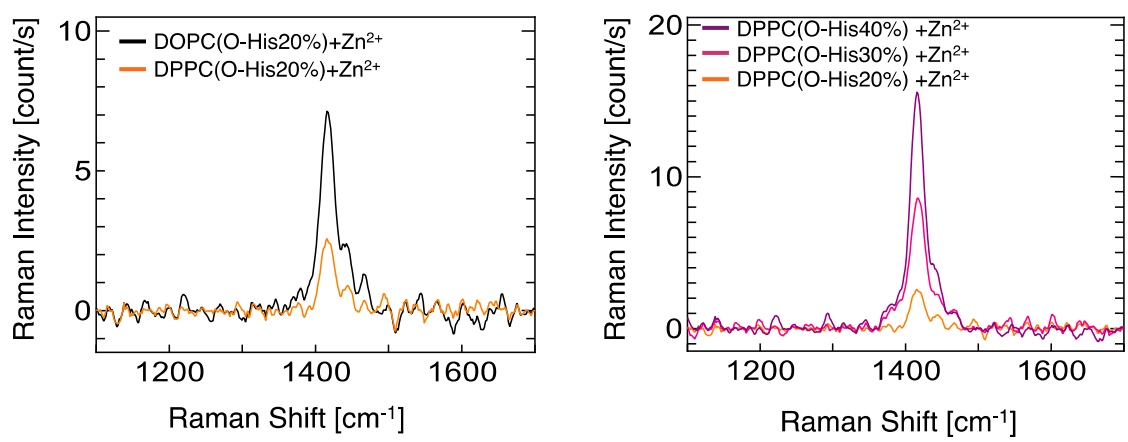

Figure 2. (a) UV resonance Raman spectra of DOPC (O-His $20 \mathrm{~mol} \%)$, in the presence or absence of $\mathrm{Zn}^{2+}$. [O-His] $=0.5 \mathrm{mM}$, [O-His] $/\left[\mathrm{Zn}^{2+}\right]=3 / 1 ;(\mathbf{b})$ UV resonance Raman spectra of DOPC (O-His $20 \mathrm{~mol} \%$ ) and DPPC(O-His $20 \mathrm{~mol} \%)$. [O-His] $=0.5 \mathrm{mM}$, [O-His] $/\left[\mathrm{Zn}^{2+}\right]=3 / 1$; (c) Dependence of $\mathrm{O}$-His concentration in DPPC liposomes. Experiments were conducted at $25{ }^{\circ} \mathrm{C}$, and the total amphiphile concentration was $2.5 \mathrm{mM}$, [O-His] $]\left[\mathrm{Zn}^{2+}\right]=3 / 1$.

\subsection{Evaluation of the Membrane Property of O-His Modified Liposomes in the Presence of $\mathrm{Zn}^{2+}$}

At room temperature, the DOPC liposome shows high fluidity (liquid-disordered phase), while the DPPC liposome shows low fluidity (solid-ordered phase). Thus O-His molecules can freely diffuse in the DOPC membrane, but are less diffusible in the DPPC membrane. For details, the membrane properties were evaluated by using fluorescence probes. 6-Lauroyl-2-dimethylamino-naphthalene (Laurdan) and 1,6-diphenyl -1,3,5-hexatriene $(\mathrm{DPH})$ reflect the inner membrane polarity and fluidity, respectively. 1,2-dioleoyl-sn- glycero-3 -phosphoethanolamine- $N$-(5-dimethylamino-1-naphthalenesulfonyl) (Dansyl-DHPE) and 1-(4-trimethy lammoniumphenyl)-6-phenyl-1,3,5-hexatriene (TMA-DPH) can be used to monitor the surface hydrophobicity and fluidity, respectively [13,19-21]. Regarding the inner properties, the $G P_{340}$ values and $1 / P$ values were hardly affected by the presence of $\mathrm{Zn}^{2+}$ (see supporting information Figure S4). This suggests that $\mathrm{Zn}^{2+}$ could not localize in the inner region of the liposomes.

In the surface properties, the hydrophobicity of O-His modified DOPC liposome became hydrophilic by adding $\mathrm{Zn}^{2+}$ (Figure 3a). This suggests that the formation of $\mathrm{Zn}$-imidazole complex could bring the water molecule onto the membrane surface. Similarly, the hydrophobicity of O-His modified DPPC liposome turned out to be slightly hydrophilic. The membrane surface fluidity of $\mathrm{O}$-His modified DOPC liposome was decreased by $\mathrm{Zn}^{2+}$, suggesting that the $\mathrm{Zn}$-imidazole complex could be in an ordered state (like liquid-ordered phase). In contrast, the addition of $\mathrm{Zn}^{2+}$ slightly increased the membrane surface fluidity of the O-His modified DPPC liposome (Figure 3b). The incorporation of a water-soluble molecule into DPPC liposome can lead the membrane to become 
fluidized [13]. In addition, the liquid-ordered phase, seen in the case of DOPC-cholesterol liposome, shows a decreased membrane surface fluidity as compared to DOPC liposome, while it shows an increased fluidity as compared to DPPC liposome [22]. Although it might be difficult to obtain direct evidence of $\mathrm{Zn}$-imidazole complex on the membrane, the varied membrane "surface" properties could reflect the interaction between $\mathrm{Zn}^{2+}$ and O-His molecules. Together with the hydrolysis activity, it could be concluded that the artificial active center is constructed by the O-His, which is modified on the liposome membrane in the presence of $\mathrm{Zn}^{2+}$ ion.

(a)

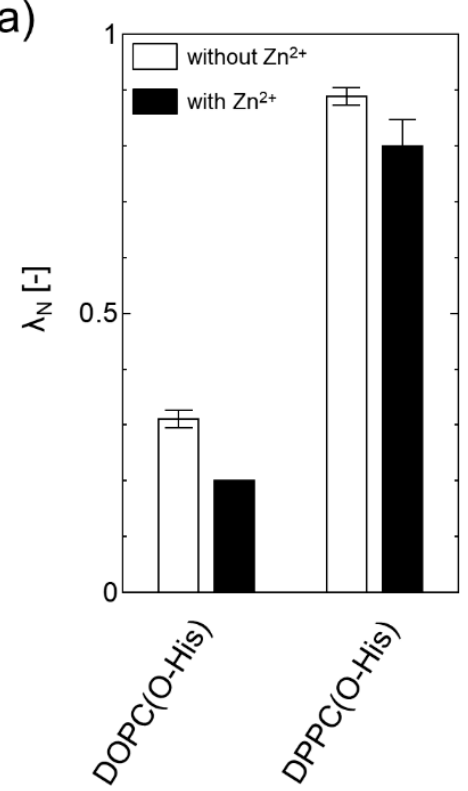

(b)

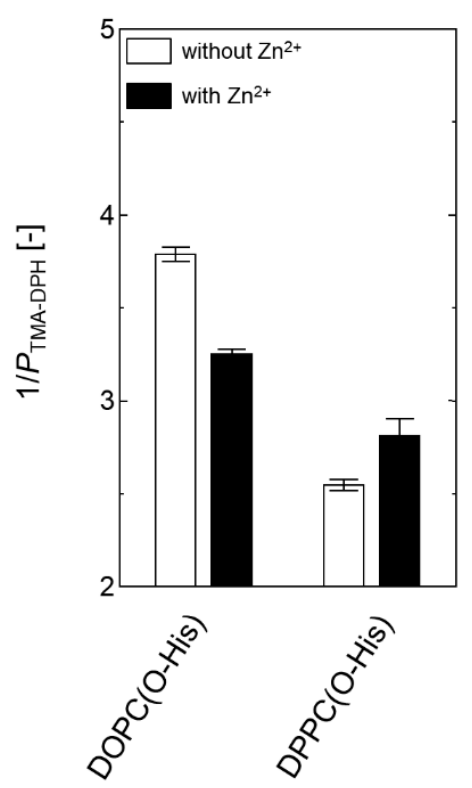

Figure 3. (a) Membrane surface hydrophobicity $\left(\lambda_{\mathrm{N}}\right)$ of liposomes. A lower $\lambda_{\mathrm{N}}$ indicates an increase of polarity; (b) Membrane surface fluidity ( $1 / P_{\text {TMA-DPH }}$ ) of liposomes. A lower $1 / P_{\text {TMA-DPH }}$ indicates a decrease of fluidity. [Total amphiphile] $=100 \mu \mathrm{M}$, [Dansyl-DHPE] $=1 \mu \mathrm{M}$, [TMA-DPH] $=0.4 \mu \mathrm{M}$ $[\mathrm{O}-\mathrm{His}]=20 \mu \mathrm{M},[\mathrm{O}-\mathrm{His}] /\left[\mathrm{Zn}^{2+}\right]=3 / 1$. Experiments were conducted at $25^{\circ} \mathrm{C}$.

\section{Conclusions}

The active site, which performed the catalytic activity like CA, was constructed at the liposome membrane surface by modifying the liposome with O-His. By adding $\mathrm{Zn}^{2+}$ into O-His modified DOPC and DPPC liposomes, the hydrolysis activities were enhanced because of the increase in substrate affinity $\left(1 / K_{\mathrm{m}}\right)$. Based on UV resonance Raman spectra, the interaction O-His with $\mathrm{Zn}^{2+}$ could be confirmed. The formation of $\mathrm{Zn}$-imidazole complex resulted in a decreased membrane surface fluidity in the DOPC membrane, together with an increase of membrane surface hydrophilicity. In natural systems (CA enzyme), both hydrophilic and hydrophobic surfaces, which are provided by polar amino acids (Asn, His, Asn, Gln, etc.) and non-polar amino acids (Phe, Val, Leu, Pro, etc.), respectively, play an important role to in hydrolysis.

Thanks to recent advances in methodology, the dynamics of enzymatic functions can be studied at a single-molecule level [23]. Some of the enzymatic reactions can be proceeded at the lipid membrane interface; e.g., phospholipase A2. The kinetic parameter obtained from conventional approaches (e.g., Lineweaver-Burk plot) might be different from the correct one [24]. A single-molecule assay will also shed a light into the enzymatic reaction at the membrane interface [25]. Such approaches will contribute to the investigation of the true role of functional ligands incorporated into liposome membranes. One of the advantages of using liposomes is that the interior region of the membrane can act as the "hydrophobic" site, then the functional ligands, such as amino acid derivatives like O-His, can be activated by the complex formation with metal ions. 


\section{Materials and Methods}

\subsection{Materials}

DOPC, DPPC, and Dansyl-DHPE were purchased from Avanti Polar Lipids, Inc. (Alabaster, AL, USA). L-His, Hydrochloric acid, chloroform, and 2-amino-2-hydroxymethyl-1,3-propanediol were purchased from Tokyo Chemical Industry Co., Ltd. (Tokyo, Japan). 1,6-Diphenyl-1,3,5-hexatriene (DPH), 6-lauroyl-2-dimethylamino-naphthalene (Laurdan), $p$-nitrophenol ( $p$-NP) and acetonitrile were obtained from Sigma Aldrich (St. Louis, MO, USA). Other chemicals were purchased from Wako Pure Chemical Industry Ltd. (Osaka, Japan) and were used without further purification. The chemical structures of lipid molecules are shown in Figure S1.

\subsection{Synthesis of $\mathrm{O}-\mathrm{His}$}

The O-His synthesis route is shown in supporting information Figure S1 [26]. In particular, oleic acid and $N$-hydroxysuccinimide were dissolved in ethyl acetate solution by mixing with a stirrer. $N, N$-dicyclohexylcarbodiimide in ethyl acetate solution was added, and stirred over one night. After the solution was stirred, $N$-hydroxysuccinimide, white precipitate, were filtered, and the filtrate was evaporated. After the obtained activated ester was recrystallized with ethanol, the product was dissolved in chloroform and added to the solution including histidine and $\mathrm{Na}^{+}$. After stirring over one night, glycine- $\mathrm{HCl}$ buffer $(0.15 \mu \mathrm{M}, \mathrm{pH}=2.0)$ and chloroform were added, and the chloroform phase was recovered by using a separation funnel. The recovered chloroform phase was evaporated and the solvent was removed. The obtained $\mathrm{O}-\mathrm{His}$ was recrystallized with chloroform, and impurities were removed. Formation of $\mathrm{O}-\mathrm{His}$ was confirmed by measurements of mass spectrum, and Raman spectrum (Figure S2).

\subsection{Liposome Preparation}

Liposomes of different compositions were prepared by the reported method [27]. Briefly, a chloroform solution of phospholipid was dried in a round-bottom flask by a rotary evaporator under a vacuum. The lipid thin film was kept under a high vacuum for at least $3 \mathrm{~h}$, and then was hydrated with Tris- $\mathrm{HCl}$ buffer $(50 \mathrm{mM}, \mathrm{pH}=8.0)$ at $60{ }^{\circ} \mathrm{C}$. The liposome suspension was frozen at $-80^{\circ} \mathrm{C}$ and was thawed at $60^{\circ} \mathrm{C}$. This freeze-thaw cycle was performed five times. The liposome suspension was extruded 11 times through two layers of polycarbonate membranes, with mean pore diameters of $100 \mathrm{~nm}$ using an extruding device (LiposoFast; Avestin Inc., Ottawa, ON, Canada). The mole fractions of liposome membrane were phospholipid/O-His $=10 / 0$ and $8 / 2$.

\subsection{Evaluation of Hydrolysis Activity}

The reaction mixture was prepared with O-His modified DOPC liposome (total amphiphile content: $2.5 \mathrm{mM}$, O-His content: $0.5 \mathrm{mM}$ ) and $\mathrm{Zn}(\mathrm{OAc})_{2}$ (total content of $\mathrm{Zn}^{2+}: 0.17 \mathrm{mM}$ ). The mixture was incubated at $25^{\circ} \mathrm{C}$ for $2 \mathrm{~h}$. After incubation, the solution was diluted with Tris- $\mathrm{HCl}$ buffer ( $50 \mathrm{mM}$, $\mathrm{pH}=8.0$, final concentration of $\mathrm{Zn}^{2+}$ was $0.1 \mathrm{mM}$ ). The reaction was initiated by adding $p$-NPA (initial concentration of 1.0, 1.5, $2.5 \mathrm{mM}$ ). The absorbance at $400 \mathrm{~nm}$, derived from $p$-NP, was measured every minute. The production rate of $p$-NP and catalytic activity were calculated by using Michaelis-Menten model and Lineweaver-Burk plot, respectively. Here, $[\mathrm{E}]_{\mathrm{T}}$ was regarded as $\left[\mathrm{Zn}^{2+}\right]$. The slope and intercept show $K_{\mathrm{m}} / V_{\max }$ and $1 / V_{\max }$, respectively. $K_{\mathrm{m}}$ and $V_{\max }$ represents the Michaelis-Menten constant and maximum reaction rate, respectively.

$$
\begin{gathered}
\mathrm{v}=\frac{V_{\max }[S]}{\left(K_{\mathrm{m}}+[S]\right)} \\
\frac{1}{v}=\frac{K_{\mathrm{m}}}{V_{\max }[S]}+\frac{1}{V_{\max }}
\end{gathered}
$$




$$
k_{c a t}=\frac{V_{\max }}{[E]_{T}}
$$

\subsection{Evaluation of Zn-Imidazole Complex by Raman Spectroscopy}

$\mathrm{Zn}(\mathrm{OAc})_{2}$ was selected as a source of $\mathrm{Zn}^{2+}$, according to literature [28]. The solutions of O-His modified DOPC liposome (total amphiphile content: $2.5 \mathrm{mM})$ and $\mathrm{Zn}(\mathrm{OAc})_{2}$ were mixed with a mole ratio of $\mathrm{O}-\mathrm{His} / \mathrm{Zn}^{2+}=3 / 1$, and the mixture was incubated at $25^{\circ} \mathrm{C}$ for $2 \mathrm{~h}$. After incubation, Raman spectra were measured using a confocal Raman microscopy (LabRAM HR-800, Horiba, Ltd., Kyoto, Japan). The $266 \mathrm{~nm}$ YAG laser of a $100 \mathrm{~mW}$ was used for excitation, and a $10 \times$ objective lens was used to focus the laser beam. All the spectra reported here were measured with an accumulation time of $20 \mathrm{~s}$, and each spectrum data was accumulated three times. The background signal of the solution was removed, and the baseline was corrected.

\subsection{Evaluation of Membrane Fluidity and Polarity}

The membrane fluidity of the liposomes was evaluated by reported methods [19-21]. The fluorescent probe DPH, TMA-DPH was added to the liposome suspension in a lipid/probe molar ratio of 250:1; the final concentrations of the lipid and probe were 100 and $0.4 \mu \mathrm{M}$, respectively. The fluorescence polarization of DPH $\left(E_{\mathrm{x}}=360 \mathrm{~nm}, E_{\mathrm{m}}=430 \mathrm{~nm}\right)$ was measured using a fluorescence spectrophotometer after incubation at $25{ }^{\circ} \mathrm{C}$ for $30 \mathrm{~min}$. The sample was excited using vertically polarized light $(360 \mathrm{~nm})$, and the emission intensities, both perpendicular $\left(I_{\perp}\right)$ and parallel $\left(I_{\|}\right)$to the excitation light, were recorded at $430 \mathrm{~nm}$. The polarization $(P)$ of DPH was then calculated from the following equations:

$$
\begin{gathered}
P=\frac{I_{\|}-G I_{\perp}}{I_{\|}+G I_{\perp}} \\
G=\frac{I_{\perp}}{I_{\|}}
\end{gathered}
$$

where $G$ is the correction factor. The membrane fluidity was evaluated on the basis of the reciprocal of polarization, $1 / P$.

Laurdan is sensitive to the polarity around the molecule itself, and its fluorescence property enables the evaluation of the surface polarity of the lipid membranes. The emission spectra were measured using a fluorescence spectrophotometer at an excitation wavelength of $340 \mathrm{~nm}$. The general polarization $\left(G P_{340}\right)$, the membrane polarity, was calculated as follows [21]

$$
G P_{340}=\frac{\left(I_{440}-I_{490}\right)}{\left(I_{440}+I_{490}\right)}
$$

where $I_{440}$ and $I_{490}$ represent the fluorescence intensity of Laurdan at 440 and $490 \mathrm{~nm}$, respectively. The total concentrations of lipid and Laurdan were 100 and $1.0 \mu \mathrm{M}$, respectively.

As for the polarity of the membrane surface, Dansyl-DHPE was used as a probe molecule and mixed in a liposome suspension, with final concentrations of lipid and Dansyl-DHPE that were 100 and $1.0 \mu \mathrm{M}$, respectively. The fluorescence spectra were analyzed by the excitation light $(336 \mathrm{~nm})$ to observe the emission peak wavelengths $(\lambda)$. The hydrophobicity of the membrane surface can be evaluated by the normalized value $\left(\lambda_{N}\right)$ by using the equation [11]

$$
\lambda_{N}=\frac{\left(\lambda-\lambda_{1}\right)}{\left(\lambda_{0}-\lambda_{1}\right)}
$$

where $\lambda_{0}$ and $\lambda_{1}$ represent the maximum wavelengths in hydrophilic $(527 \mathrm{~nm})$ and hydrophobic $(512 \mathrm{~nm})$ conditions, respectively. 


\subsection{Statistical Analysis}

Results are expressed as mean \pm standard deviation. All experiments were performed at least three times.

Supplementary Materials: The following are available online at http:/ /www.mdpi.com/2504-5377/2/2/24/ s1. Figure S1: Synthesis scheme for O-His; Figure S2: MS spectrum and Raman spectra of O-His; Figure S3: Lineweaver-Burk plot of DPPC (O-His) $+\mathrm{Zn}^{2+}$; Figure S4: Liposome membrane inner properties.

Author Contributions: A.T. and K.S. performed experiments. A.T., K.S. and H.U. wrote paper. A.T., K.S. and H.U. directed the research.

Acknowledgments: This research was supported by the Japan Society for the Promotion of Science (JSPS) Grant-in-Aid for Scientific Research A (26249116), JSPS Grant-in-Aid for Young Scientist B (16K18279), and JSPS Grant-in-Aid for Challenging Exploratory Research (T15K142040).

Conflicts of Interest: There are no conflicts of interest to declare.

$\begin{array}{ll}\text { Abbreviations } \\ \text { CA } & \text { carbonic anhydrase } \\ \text { O-His } & \text { oleoyl-histidine } \\ p \text {-NPA } & \text { p-nitrophenylacetate } \\ \text { DOPC } & \text { 1,2-dioleoyl-sn-glycero-3-phosphocholine } \\ \text { DPPC } & \text { 1,2-dipalmitoyl-sn-glycero-3-phosphocholine } \\ \text { Dansyl-DHPE } & \text { 1,2-dioleoyl-sn-glycero-3-phosphoethanolamine- } N \text {-(5-dimethylamino-1-naphthalenesulfonyl) } \\ \text { Laurdan } & \text { 6-lauroyl-2-dimethylamino-naphthalene } \\ \text { DPH } & \text { 1,6-diphenyl-1,3,5-hexatriene (DPH), } \\ \text { TMA-DPH } & \text { 1-(4-trimethylammoniumphenyl)-6-phenyl-1,3,5-hexatriene } \\ p \text {-NP } & p \text {-nitrophenol }\end{array}$

\section{References}

1. Savile, C.K.; Lalonde, J.J. Biotechnology for the acceleration of carbon dioxide capture and sequestration. Curr. Opin. Biotechnol. 2011, 22, 818-823. [CrossRef] [PubMed]

2. Krishnamurthy, V.M.; Kaufman, G.K.; Urbach, A.R.; Gitlin, I.; Gudiksen, K.L.; Weibel, D.B.; Whitesides, G.M. Carbonic Anhydrase as a Model for Biophysical and Physical-Organic Studies of Proteins and Protein-Ligand Binding. Chem. Rev. 2008, 108, 946-1051. [CrossRef] [PubMed]

3. Sahoo, P.C.; Jang, Y.-N.; Lee, S.-W. Immobilization of carbonic anhydrase and an artificial Zn (II) complex on a magnetic support for biomimetic carbon dioxide sequestration. J. Mol. Catal. B Enzym. 2012, 82, 37-45. [CrossRef]

4. Sahoo, P.C.; Jang, Y.-N.; Suh, Y.-J.; Lee, S.-W. Bioinspired design of mesoporous silica complex based on active site of carbonic anhydrase. J. Mol. Catal. A Chem. 2014, 390, 105-113. [CrossRef]

5. Cioci, F.; Lavecchia, R.; Marrelli, L. Effect of surface tension on the conformational stability of erythrocyte carbonic anhydrase. Fluid Phase Equilib. 1996, 116, 118-125. [CrossRef]

6. Juan, D.; Bingying, J.; Xingming, K.; Xiancheng, Z.; Qingxiang, X. Enhanced Hydrolysis of Carboxylic Acid Esters Catalyzed by Metallomicelles Made of $\mathrm{Cu}(\mathrm{II})$ and $\mathrm{Zn}(\mathrm{II})$ Complexes. J. Colloid Interface Sci. 2002, 256, 428-434. [CrossRef]

7. Poznik, M.; König, B. Cooperative hydrolysis of aryl esters on functionalized membrane surfaces and in micellar solutions. Org. Biomol. Chem. 2014, 12, 3175-3180. [CrossRef] [PubMed]

8. Garcia-Rio, L.; Mejuto, J.C.; Perez-Lorenzo, M. Modification of reactivity by changing microemulsion composition. Basic hydrolysis of nitrophenyl acetate in AOT/isooctane/water systems. New. J. Chem. 2004, 28, 988-995. [CrossRef]

9. Kim, M.-C.; Lee, S.-Y. Carbonic Anhydrase-Mimetic Bolaamphiphile Self-Assembly for $\mathrm{CO}_{2}$ Hydration and Sequestration. Chem. Eur. J. 2014, 20, 17019-17024. [CrossRef] [PubMed]

10. Walde, P.; Umakoshi, H.; Stano, P.; Mavelli, F. Emergent Properties Arising from the Assembly of Amphiphiles. Artificial vesicle membranes as reaction promoters and regulators. Chem. Commun. 2014, 50, 10177-10197. [CrossRef] [PubMed] 
11. Ishigami, T.; Tauchi, A.; Suga, K.; Umakoshi, H. Effect of Boundary Edge in DOPC/DPPC/Cholesterol Liposomes on Acceleration of L-Histidine Preferential Adsorption. Langmuir 2016, 32, 6011-6019. [CrossRef] [PubMed]

12. Metso, A.J.; Zhao, H.; Tuunainen, I.; Kinnunen, P.K.J. Observation of the main phase transition of dinervonoylphosphocholine giant liposomes by fluorescence microscopy. Biochim. Biophys. Acta 2005, 1713, 83-91. [CrossRef] [PubMed]

13. Zhao, J.; Wu, J.; Heberle, F.A.; Mills, T.T.; Klawitter, P.; Huang, G.; Costanza, G.; Freigenson, G.W. Phase studies of model biomembranes: Complex behavior of DSPC/DOPC/Cholesterol. Biochim. Biophys. Acta 2007, 1768, 2764-2776. [CrossRef] [PubMed]

14. Christianson, D.W.; Fierke, C.A. Carbonic Anhydrase: Evolution of the Zinc Binding Site by Nature and by Design. Acc. Chem. Res. 1996, 29, 331-339. [CrossRef]

15. Pocker, Y.; Stone, T. The Catalytic Versatility of Erythrocyte Carbonic Anhydrase. III. Kinetic Studies of the Enzyme-Catalyzed Hydrolysis of p-Nitrophenyl Acetate. Bichemistry 1967, 6, 668-678. [CrossRef]

16. Suga, K.; Hamasaki, A.; Chinzaka, J.; Umakoshi, H. Liposomes modified with cardiolipin can act as a platform to regulate the potential flux of $\mathrm{NADP}^{+}$-dependent isocitrate dehydrogenase. Metab. Eng. 2016, 3, 8-14. [CrossRef] [PubMed]

17. Mesu, J.G.; Visser, T.; Soulimani, F.; Weckhuysen, B.M. Infrared and Raman spectroscopic study of $\mathrm{pH}$-induced structural changes of L-histidine in aqueous environment. Vib. Spectrpsc. 2005, 39, 114-125. [CrossRef]

18. Salama, S.; Spiro, T.G. Resonance Raman Spectra of Cobalt(II)-Imidazole Complexes: Analogues of the Binding Site of Cobalt-Substituted Zinc Proteins. J. Am. Chem. Soc. 1978, 100, 1105-1111. [CrossRef]

19. Lentz, B.R. Membrane "fluidity" as detected by dipheylhexatriene probes. Chem. Phys. Lipids 1989, 50, 171-190. [CrossRef]

20. Hayashi, K.; Shimanouchi, T.; Kato, K.; Miyazaki, T.; Nakamura, A.; Umakoshi, H. Investigation of Fatty Acid Ketohydrazone Modified Liposome's Properties as a Drug Carrier. Colloids Surf. B 2011, 87, $28-35$. [CrossRef] [PubMed]

21. Parasassi, T.; Krasnowska, E.-K.; Bagatolli, L.; Gratton, E. Laurdan and Prodan as Polarity-Sensitive Fluorescent Membrane Probes. J. Fluoresc. 1998, 8, 365-373. [CrossRef]

22. Bui, T.T.; Suga, K.; Umakoshi, H. Roles of Sterol Derivatives in Regulating the Properties of Phospholipid Bilayer Systems. Langmuir 2016, 32, 6176-6184. [CrossRef] [PubMed]

23. Jørgensen, S.K.; Hatzakis, N.S. Insights in enzyme functional dynamics and activity regulation by single molecule studies. Biophys. Rev. Lett. 2013, 8, 137-160. [CrossRef]

24. Rabe, M.; Tabaei, S.R.; Zetterberg, H.; Zhdanov, V.P.; Höök, F. Hydrolysis of a lipid membrane by single enzyme molecules: Accurate determination of kinetic parameters. Angew. Chem. Int. Ed. 2015, 54, 1022-1026. [CrossRef] [PubMed]

25. Gunnarsson, A.; Snijder, A.; Hicks, J.; Gunnarsson, J.; Höök, F.; Geschwindner, S. Drug discovery at the single molecule level: Inhibition-in-solution assay of membrane-reconstituted $\beta$-secretase using single-molecule imaging. Anal. Chem. 2015, 87, 4100-4103. [CrossRef] [PubMed]

26. Lapidot, Y.; Rappoport, S.; Wolman, Y. Use of esters of $N$-hydroxysuccinimide in the synthesis of $N$-acylamino acids. J. Lipid Res. 1967, 8, 142-145. [PubMed]

27. MacDonald, R.C.; MacDonald, R.I.; Menco, B.P.H.M.; Takeshita, K.; Subbarao, N.K.; Hu, L.-R. Small-volume extrusion apparatus for preparation of large, unilamellar vesicles. BBA Biomembr. 1991, 30, 297-303. [CrossRef]

28. Kim, M.-C.; Lee, S.-Y. Comparative Study on the Catalytic Hydration of Carbon Dioxide by Catalysts that Mimic Carbonic Anhydrase Prepared with Zinc Salts. ChemCatChem 2015, 7, 698-704. [CrossRef]

(C) 2018 by the authors. Licensee MDPI, Basel, Switzerland. This article is an open access article distributed under the terms and conditions of the Creative Commons Attribution (CC BY) license (http://creativecommons.org/licenses/by/4.0/). 